Citius, Altius, Fortius-2021, 14(2), pp. 35-40

\title{
LOS JUEGOS DEPORTIVOS ESCOLARES «SANTA FE JUEGA» ¿UNA OPORTUNIDAD PARA EL DESARROLLO DE DEPORTISTAS?
}

\author{
Cristian David Rodríguez Piñero \\ Universidad Nacional de Avellaneda (Argentina) \\ cristian.rodpi@hotmail.com
}

Fecha de recepción: septiembre 2021

Fecha de aceptación: noviembre 2021

http://doi.org/10.15366/citius2021.14.2.003

\section{Resumen:}

El presente artículo persigue el objetivo de ser un análisis interpretativo sobre los Juegos Deportivos Escolares Santa Fe Juega. Estos juegos escolares se desarrollan todos los años en diversas etapas en la provincia de Santa Fe, Argentina. Este evento ha sido analizado bajo las categorías Deporte- Educación Física y Deporte - Política. Se examina cómo este evento, que brinda oportunidades a algunos jóvenes, condiciona a que quizás el talento de otros quede bajo la sombra de una competencia desleal al juntarse a atletas que compiten en federaciones deportivas, junto con atletas quienes, a pesar de quizás tener talento, no tienen esta oportunidad. Es por ello, que como conclusión se propone la separación de los participantes en categorías, para poder dar igualdad de oportunidades y de crecimiento deportivo, tanto a atletas federados como a atletas no federados, incentivando de este modo el progreso a los deportistas más novatos.

Palabras Clave: Educación y Entrenamiento Físico, Deportes, Políticas Públicas, Rendimiento Atlético

Title: SPORTS GAMES "SANTA FE JUEGA": AN OPPORTUNITY FOR THE DEVELOPMENT OF ATHLETES?

\begin{abstract}
:
This article has the objective of be an interpretive analysis of the Santa Fe Juega School Sports Games. These school games take place every year at various stages in the province of Santa Fe, Argentina. This event will be analyzed under the categories Sport-Physical Education and Sport-Politics in order to understand this event that provides opportunities to some young people and perhaps the talent of other, who are under the shadow of an unfair competition in which athletes who compete in sports federations together with athletes despite perhaps having talent, they do not have this opportunity. That is the reason this event should separate the participants into categories in order to give equal opportunities and sports growth to both federated and non-federated athletes, giving chance to beginner athletes to progress.
\end{abstract}

Keywords: Physical Education and Training, Sports, Public Policy, Athletic Performance

\section{Introducción}

La Convención sobre los Derechos del Niño de la ONU declara en su artículo 31: «Los Estados Parte respetarán y promoverán el derecho del niño a participar plenamente en la vida cultural y artística y propiciarán oportunidades apropiadas, en condiciones de igualdad, de participar en la vida cultural, artística, recreativa y de esparcimiento.» (pp. 23-24). 
El presente trabajo pretende realizar un análisis interpretativo de la normativa que rige los Juegos Deportivos Escolares conocidos con el nombre de «Santa Fe Juega» bajo la óptica de las categorías Deporte-Educación Física y Deporte-Política.

Desde la escuela secundaria es posible fomentar diversas estrategias y actividades como lo pueden ser la participación en juegos inter escolares o la visita a diversos eventos deportivos en la ciudad o cercanías a los fines de poder conocer los diversos deportes que pueden practicar en el barrio o en la ciudad. (Rodríguez Piñero, p. 59, 2021).

Santa Fe Juega es un programa provincial, deportivo y cultural, implementado desde 2008 en todo el territorio de la provincia de Santa Fe, Argentina. En su edición 2018 participaron de la iniciativa 180.000 jóvenes; niñas y niños de 11 a 18 años pertenecientes a más de 300 localidades del territorio provincial.

El objetivo de la propuesta es propiciar la convivencia, la participación y la apropiación del espacio público mediante actividades deportivas y artísticas. Existen posibilidades de participación que van desde la iniciación deportiva (Encuentros de atletismo y balónmano orientados a sexto y séptimo grado), hasta el alto rendimiento (más de 30 deportes con instancias de participación departamental, provincial y nacional), pasando por jornadas recreativas (Juegos en Red y Entretiempos) y la iniciativa cultural.

El interés en este tema surge a raíz de la articulación que debería haber entre Deporte escolar y Deporte Federado en la provincia de Santa Fe (Argentina), así como también en la motivación por la continuidad en el deporte por parte de los jóvenes federados una vez concluida la etapa de la escuela secundaria, accediendo a los estudios superiores terciarios o universitarios, compatibilizándolos con el deporte en lo que se conoce como «doble carrera».

Carballo y Hernández (1999) afirma: «el llamado deporte escolar o educativo no es el producto de la transposición didáctica del deporte configurado socialmente por federaciones y medios de comunicación sino una creación de la Educación Física Escolar» (p. 15). Es por ello importante lograr una eficiente articulación entre deporte escolar y su continuidad con el deporte federado y la práctica deportiva una vez finalizada la escuela.

\section{Desarrollo}

\subsection{Deporte - Educación Física}

Cuando hacemos referencia a la palabra deporte, podemos comenzar con un análisis etimológico de la palabra, llegando a pensar en la misma como una construcción cultural, que, a través de los siglos, ha ido transformando su significado a través de los diversos contextos y acontecimientos históricos que se fueron sucediendo a lo largo de la historia, hasta llegar a ser lo que hoy en esta primera parte del siglo XXI entendemos como Deporte. «El concepto de deporte es polisémico: como toda construcción cultural es interpretable y sus significados varían según el origen de las miradas que sobre él se arrojen.» (Carballo y Hernández, 1999, p.2). Estos mismos

autores hacen mención a Carl Diem, quien afirma que «Cada época crea su deporte y la esencia de cada pueblo se refleja en él.» (p.1)

Carballo y Hernández (1999) referencian a Parlebas, quien sostiene que: 
«(...) el deporte es una práctica competitiva, reglada e institucionalizada, que se organiza en torno a un sistema económico determinado y cuya institucionalidad política se centra en la reproducción del orden vigente, del cual el deporte es a la vez producto y productor. El segundo camino posible es darle a la definición original del autor un carácter general que merecería ser especificado en el contexto histórico.» (p.15)

El objeto de análisis será la normativa del programa provincial, deportivo y cultural conocido como Santa Fe Juega, en base a esta propuesta que se lleva a cabo desde hace ya más de una década, y que articula la Educación Física escolar con esta propuesta deportiva. El evento Santa Fe Juega, es apreciado y esperado todos los años por los alumnos de las escuelas secundarias. En este evento, tienen la posibilidad de participar en un deporte representando a su Institución Educativa, lo cual es en sí mismo una motivación importante para ellos. En relación con esto, «la educación física se vio necesitada metodológicamente de la utilización de los juegos deportivos como elemento motivador y de distensión» (Vázquez,1989, p. 79). Es por ello que, Cagigal (1975) afirma que «hoy, hablar de deporte y educación física como entidades independientes, es un anacronismo» (citado en Vázquez, 1989, p.79)

Podemos decir que la Educación Física y el Deporte van de la mano. La Educación Física como disciplina escolar se ha nutrido prácticamente desde siempre del deporte, tanto lo ha hecho que muchas veces pareciera ser subsidiaria de él. A pesar de las controversias, la Educación Física es «el único ámbito legitimado por la escuela donde lo motriz es pertinente y socialmente significativo y en cuyo espacio se puede intervenir programáticamente sobre el desarrollo motriz de los ciudadanos» (Rodríguez,1996, p.4).

Es en este evento en el que se visibiliza el vínculo entre Educación Física y Deporte, ya que el Santa Fe Juega lleva a que las clases de Educación Física se planifiquen en función del evento. Por ejemplo, si se inscribió a varios alumnos de un curso para presentarse a competir en atletismo, las clases van a tener muchos contenidos sobre este deporte hasta que se terminen las competencias. «El deporte es para el sistema educativo argentino un contenido que continúa la obra iniciada por los juegos motores reglados y funda su educatividad en la medida que ofrece oportunidad para el desarrollo.» (Carballo y Hernández,1999, p.14).

Esto se evidencia en el evento Santa Fe Juega, ya que genera gran expectativa en los alumnos que participan, siendo una gran herramienta de motivación para los adolescentes, entre quienes muchas veces, es difícil generar interés por ciertas actividades. En relación con esto último, podemos afirmar que «el deporte es el fenómeno cultural más importante de la sociedad contemporánea. Este enunciado suele desarrollarse y reforzarse de distintas formas.» (Barbero, 1993, p.9).

En estos eventos deportivos, aparecen jóvenes talentos. Es cierto que muchas veces ya destacaban sobre el resto en las clases de Educación Física y fue este el motivo por el que fueron seleccionados para participar. Esto se evidencia en los deportes competitivos como el atletismo en el que uno se rige bajo el patrón del tiempo y marca.

En relación con este punto, Benilde Vázquez Gómez, afirma que:

«La enseñanza de los deportes con objetivos fundamentalmente de rendimiento y competición ha supuesto indirectamente la elección espontánea, cuando no provocada por los mismos profesores, 
de los más capacitados, de los mejores, y el abandono más o menos explícito de los menos dotados o de los menos motivados» (citado en Carballo, 2003, p.55).

Si tenemos en cuenta que muchos jóvenes tienen un desarrollo tardío, o demoran quizás más tiempo en lograr aprender una técnica o una disciplina nueva dependiendo de sus capacidades, esto lleva a la deserción de muchos jóvenes, los cuales seguramente podrían también llegar a tener logros interesantes a nivel deportivo. Esto también se da muchas veces con el alumnado que participa en Santa Fe Juega en atletismo, por ejemplo, y procede de la práctica de deportes de equipo como el fútbol o el rugby. Es el caso de aquellos que quizás tras destacar en algún lanzamiento o carrera, en cuanto avanzan de etapas y les toca competir con algún joven atleta federado, el atleta federado suele ser quién los deja afuera de la siguiente etapa, siendo los federados quienes se clasifican para la final nacional de los Juegos Evita. Aquí entramos en la disyuntiva de si es justo o no que compitan atletas federados contra los no federados. Años atrás, esto no estaba permitido en las competencias inter-escolares en la provincia de Santa Fe, Argentina. Este tema es un tópico para larga discusión y entraría en un capítulo aparte en este trabajo. Probablemente, un joven con talento y poca experiencia no federada, que quizás tiene condiciones para un deporte, estaría quedando fuera de competencia y, la consecuente frustración, quizás pueda llevarle a no continuar practicando ese deporte.

\subsection{Deporte - Política}

El evento deportivo Santa Fe Juega, es una política implementada por el Gobierno de Santa $\mathrm{Fe}$, con el fin de generar en los jóvenes un interés por la participación en actividades lúdicas, deportivas y culturales; incentivando a los mismos a participar de dicho evento en representación de su Establecimiento Educativo, y de lograr pasar las sucesivas etapas, llegar a competir en la final nacional: los Juegos Evita.

Existe lo que podemos calificar como un «quiebre entre las políticas educativas, las comunitarias y las de alto rendimiento». (Rodríguez, 1996, p.5). Es por ello, que muchas veces este tipo de eventos terminan siendo una imagen y publicidad política para el gobierno de turno, el cuál siempre suele jactarse de la cantidad de participantes que hay en el mismo o de inaugurar alguna infraestructura nueva. Hay que reconocer, que este tipo de eventos, dan la oportunidad al alumnado con talento de poder ser «descubiertos» en algún deporte y quizás continuar en el mismo en un futuro entrenando y practicándolo de modo más comprometido y en mejores condiciones de entrenamiento e infraestructura.

Un punto que criticar de esta política es que no se toma en cuenta la articulación del deporte de base o del deporte escolar con el deporte de Alto Rendimiento. La mayoría de los jóvenes que participan en este evento en deportes individuales y llegan a las instancias más elevadas como lo son los Juegos Evita, suelen ser los deportistas federados.

El desafío sería lograr una «Articulación del deporte en una política global que dé cuenta de las prácticas escolares, comunitarias y de alto rendimiento.» (Rodríguez, 1996, p. 5)

Respecto a los Juegos Olímpicos es preciso considerar que:

«El llamado mayor espectáculo del mundo contemporáneo se convierte en una cuestión de Estado y desde las distintas instancias de poder, tanto públicas como privadas, se trata de generar un 
consenso que permita tomar importantes decisiones de carácter económico, político y cultural, que en otras circunstancias serían mucho más problemáticas.» (Barbero, 1993, p.35)

Comparando grandes eventos multideportivos como lo son los Juegos Olímpicos, salvando las grandes diferencias estructurales entre estos eventos deportivos escolares como es el caso de Santa Fe Juega y los Juegos Evita, podemos decir que son estas instancias en las que se puede sacar provecho a la aparición de nuevos talentos deportivos, articulando su continuidad en el deporte una vez fuera del sistema escolar o en simultaneidad con él, explotando ese talento y motivando a la juventud a poder desarrollarse en el deporte a través de becas y estímulos para el desarrollo deportivo.

\section{Conclusiones}

El evento Santa Fe Juega claramente podría estar articulado a otras políticas deportivas que den una continuidad en el desarrollo deportivo. No se trata solo de educar para el deporte, como si este fuese el logro mayor de la educación física, sino de educar a través del deporte. No hay oposición, además, entre deporte y educación física, ya que la actividad deportiva es considerada como un sistema de educación, tanto sea entrenamiento físico o simplemente recreación (Listello, 1959). El método deportivo utiliza como centro de interés el gusto durante la infancia por las actividades deportivas para, a través de ellas, alcanzar una formación completa, física, moral y social, y a la vez extender el gusto por estas actividades más allá de la edad escolar.

Sería importante la incorporación de una reglamentación que regule la participación de los atletas federados y no federados. Actualmente ambos participan en una misma competencia, esta circunstancia propicia que los no federados son muchas veces desplazados en las primeras etapas, generando una competencia totalmente desleal en la que son muy pocos los participantes no federados que logran llegar a la final nacional de los Juegos Evita. Como política provincial, sería interesante aprovechar el recurso que brinda el deporte, en este caso con el Santa Fe Juega, para que los jóvenes santafesinos puedan continuar una vez finalizada su etapa escolar no solo practicando deporte, sino aprendiendo un oficio o estudiando una carrera terciaria o universitaria. La Federación del Deporte Universitario Argentino, propone lo que se denomina el Proyecto: Doble Carrera. Este proyecto se propone vincular a deportistas en edad universitaria y preuniversitaria, con instituciones de nivel superior de todo el país, para que puedan desarrollar su trayectoria deportiva y académica sin tener que elegir entre una de ellas. Lo que se pretende es poder ofrecer a estos deportistas una doble posibilidad: la de estudiar una carrera universitaria al tiempo que fortalecer su carrera deportiva, dando continuidad así, a los frutos que puede brindar el Santa Fe Juega a largo plazo. Si este evento genera un gusto por el deporte en la mayoría de los participantes, conseguiremos tener una población con gusto por una vida más saludable, y quizás podremos pensar que en el futuro puedan desarrollar una vida adulta sana practicando actividad física y consiguiendo un envejecimiento activo saludable.

\section{Bibliografía y fuentes}

Barbero, J. (1993). Introducción. En J. Barbero, Materiales de sociología del deporte. Ediciones de La Piqueta.

Carballo, C. (2003) Proponer y Negociar. El ocaso de las tradiciones autoritarias en las prácticas de la Educación Física. Ediciones Al Margen. 
Carballo, C. y Hernández, N. (1999). Acerca del concepto de deporte. Alcances de su(s) significado(s). Revista Educación Física \& Ciencia, 6, 87-102.

Federación del Deporte Universitario Argentino (FEDUA). Proyecto Doble Carrera. Recuperado el 21/07/2020 de http://feduargentina.com.ar/proyecto-doble-carrera/\#

Listello, A. (1959). Orientation sportive. Editions Bourrelier.

Ministerio de Desarrollo Social de la Provincia de Santa Fe (5 de abril de 2019). Santa Fe Juega. Gobierno de la Provincia de Santa Fe. Recuperado el 21/07/2020 de https://www.santafe.gov.ar/index.php/web/content/view/full/153947/(subtema)/93753

Organización de las Naciones Unidas (ONU) (20 de noviembre de 1989). Convención sobre los Derechos del Niño. Recuperado el 20/07/2020 de https://www.un.org/es/events/childrenday/pdf/derechos.pdf

Rodríguez, M. (1996). Minuto, juez. Deporte, sociedad y escuela. Revista digital efdeportes.com. Recuperado el 14 de febrero de 2014, desde http://www.efdeportes.com/efd1/12mgrd.htm

Rodríguez Piñero, C. D. (2021). Rendimiento Académico en estudiantes de nivel secundario y su relación con la práctica deportiva extraescolar. EmásF, Revista Digital de Educación Física, 13(73), 48-61.

Vázquez G., B. (1989). La educación física en la educación básica. Gymnos. 